\title{
ANÁLISE DO USO DE AGROTÓXICOS EM ESPAÇOS DE RIZICULTURA: UM ESTUDO DE CASO NO MUNICÍPIO DE CAÇAPAVA, SP.
}

\author{
João Batista Alves dos Santos ${ }^{1}$ \\ Milena Bruzaferro Pinto ${ }^{2}$ \\ Sara Costa Brito $^{3}$ \\ Marcele Cantarelli Trevisan Nunez ${ }^{4}$ \\ Jobair Assis Rangel ${ }^{5}$
}

Resumo: O presente trabalho apresenta um estudo, de caráter teórico-prático, do uso de agrotóxicos em espaço destinado para a rizicultura, na região de Caçapava, SP. O desenvolvimento do mesmo foi dividido em três etapas, que consistem em: leitura sobre artigos e livros relacionados à temática estabelecida, análise da área de estudo, que trata-se de uma área predominantemente ocupada pela rizicultura (cultivo de arroz) e que também é favorecida pela qualidade do solo e disponibilidade de recursos hídricos para atender a plantação e, por fim, a análise química das amostras recolhidas. A etapa da análise química foi desenvolvida no Laboratório Central Multiusuário, localizado no Instituto de Pesquisa e Desenvolvimento, da Universidade do Vale do Paraíba. Após a realização das três etapas, ficou constatada a presença de diversos elementos químicos, tais como carbono e oxigênio, porém, não houve a presença de metais tóxicos nos grãos analisados.

Palavras-chave: Agrotóxicos, Rizicultura e Contaminação.

\footnotetext{
${ }^{1}$ Química/Colégios Univap-Centro, Brasil. E-mail: jbatistasjc@gmail.com.

2 Química/Colégios Univap-Centro, Brasil. E-mail: bruzaferromilena@gmail.com.

3 Química/Colégios Univap-Centro, Brasil. E-mail: sarahcosta20@hotmail.com.

4 Química/Colégios Univap-Centro, Brasil. E-mail: marcelenunez@gmail.com.

${ }^{5}$ Química/Colégios Univap-Centro, Brasil. E-mail: jobairrangel@terra.com.br.
} 